\title{
REDUCING UNCERTAINTY IN PREDICTION OF DUNE EROSION DURING EXTREME CONDITIONS
}

\author{
C. (Kees) den Heijer ${ }^{1,2}$, Ad J.H.M. Reniers ${ }^{1,3}$, Jan van de Graaff ${ }^{1}$ and Pieter H.A.J.M. \\ van Gelder ${ }^{1}$
}

\begin{abstract}
Coastal dunes protect low lying coastal areas against the sea. Extreme waves and water levels during severe storms may cause breaching of the dunes. Consequently, serious damage due to flooding and direct wave attack could occur, resulting in loss of life and property. Proper coastal management implies that reinforcement measures will be taken if the actual safety level does not meet the agreed standard. In order to cope with small probabilities of failure, which are relevant for the Dutch dune coast, a proper safety assessment method is required. Various aspects, which are currently considered as relevant for dune erosion, are not included in the present safety assessment method. This study concerns (1) an approach to reduce the uncertainty in dune erosion prediction as well as (2) a probabilistic sensitivity analysis of various variables that are included in the current Dutch safety assessment method. The aim of the latter part is to get more insight in the influence of the stochastic characteristics of the various variables which are taken into account in the current method. The calculation values which are used for the actual safety assessment, in a semi-deterministic way, are based on a full probabilistic investigation. This full probabilistic investigation has been used as a reference for the present sensitivity analysis, in which all stochastic characteristics have been varied. Both the deterministic DUROS+ model, which is used in the current safety assessment method, as well as the process based DUROSTA model have been applied. Main conclusion is that for both DUROS+ and DUROSTA the stochastic characteristics for the water level and the grain size are the most important for the prediction of dune erosion.
\end{abstract}

\section{INTRODUCTION}

A large part of The Netherlands is protected by coastal dunes. Moreover, this large part of the country refers to the area with the most economical value and is mainly below mean sea level. Therefore, a proper assessment of the safety of the dune coast is very important. Law prescribes a maximum probability of failure of the dune coast of $10^{-5}$ per year (for the most important parts of the coast; for other parts, probabilities are slightly larger). A safety assessment, to check whether the prescribed safety level is met, has to be carried out every five years.

${ }^{1}$ Section of Hydraulic Engineering, Delft University of Technology, P.O. Box 5048, Delft, 2600 GA, The Netherlands

${ }^{2}$ Deltares, P.O. Box 177, Delft, $2600 \mathrm{MH}$, The Netherlands

${ }^{3}$ Division of Applied Marine Physics, Rosenstiel School of Marine and Atmospheric Science, University of Miami, 4600 Rickenbacker Causeway, Miami, FL 33149, USA 
The dune safety assessment method, presently used for the Dutch coast, is based on TAW (1984) and was recently adapted by WL/Delft Hydraulics (2007b) to account for wave period influence. Basically the method is 2D. However, various aspects which might play a role in the dune erosion process are still not included in the current safety assessment method. These aspects include storm characteristics, foreshore bathymetry, variability in bathymetry, longshore variability, structures and other special structural elements as well as the time dependent process modeling of dune erosion. The omission of the uncertainties introduced by these aspects might affect a proper evaluation of the safety of the Dutch dune coasts. If the current safety assessment method would be too conservative, the costs for coastal maintenance could be reduced. But otherwise, if the dune coast is less safe than assumed so far, strengthening measures might be urgently needed.

\section{Current safety assessment method}

Within the dune safety assessment method, as currently used in The Netherlands, a rather simple empirical dune erosion model (DUROS+; WL | Delft Hydraulics, 2007b) is used. The model uses hydraulic conditions at the MSL $-20 \mathrm{~m}$ depth contour. Based on these conditions as well as the fall velocity (related to the grain size), an after storm cross-shore profile shape is defined. Using the principle of cross-shore conservation of volume, the position of the after storm profile, the result of the DUROS+ model, can be found. The safety assessment method prescribes an additional contribution for divergent storm duration and model inaccuracy. Relative to the erosion volume above storm surge level resulting from DUROS+, an additional volume is enclosed by shifting the dune front in cross-shore direction, to contribute for divergent storm duration and model inaccuracy.

For the actual assessment, calculation values are used for (maximum) storm surge level, wave height, wave period and storm duration at the load side, and grain size as well as the cross-shore profile at the strength side, together with a contribution for the model inaccuracy. The calculation values are derived based on a full probabilistic investigation.

The variables, currently included in the safety assessment, can be considered as the main governing parameters for the dune erosion process. However, more variables play a role, and currently included variables can yield to better results when applying a more sophisticated dune erosion model.

\section{Objective}

Improvement of the safety evaluation is only possible if reduction of the overall uncertainty can be provided. It is therefore crucial to identify the variables and processes involved, and the corresponding uncertainties. The sensitivity of the rate of dune erosion for each of the involved variables shows how the uncertainty of those variables is influencing the dune erosion prediction.

This paper has a double aim. The first aim is to outline an approach to reduce the uncertainty in dune erosion prediction. The second aim is to get more 
insight in the sensitivity of the rate of dune erosion for the variables which are currently included in the Dutch safety assessment method. The main focus is on the situation for a probability of failure of $10^{-5}$ per year, being the design criterion for the largest part of the Dutch dune coast. Apart from the DUROS+ (TAW, 1984; WL | Delft Hydraulics, 2007b) model, as currently applied in the safety evaluation, also the results for the process based DUROSTA model (Steetzel, 1993) will be described in this paper.

\section{APPROACH}

The present paper describes some first steps in a research to reduce the uncertainty in dune erosion prediction. To place the present paper in the right perspective, this section first outlines the overall approach before focusing on the approach of the present part: a probabilistic sensitivity analysis.

\section{Process chain}

A cross-shore dune erosion process chain has been outlined in Figure 1, starting offshore, going onshore.

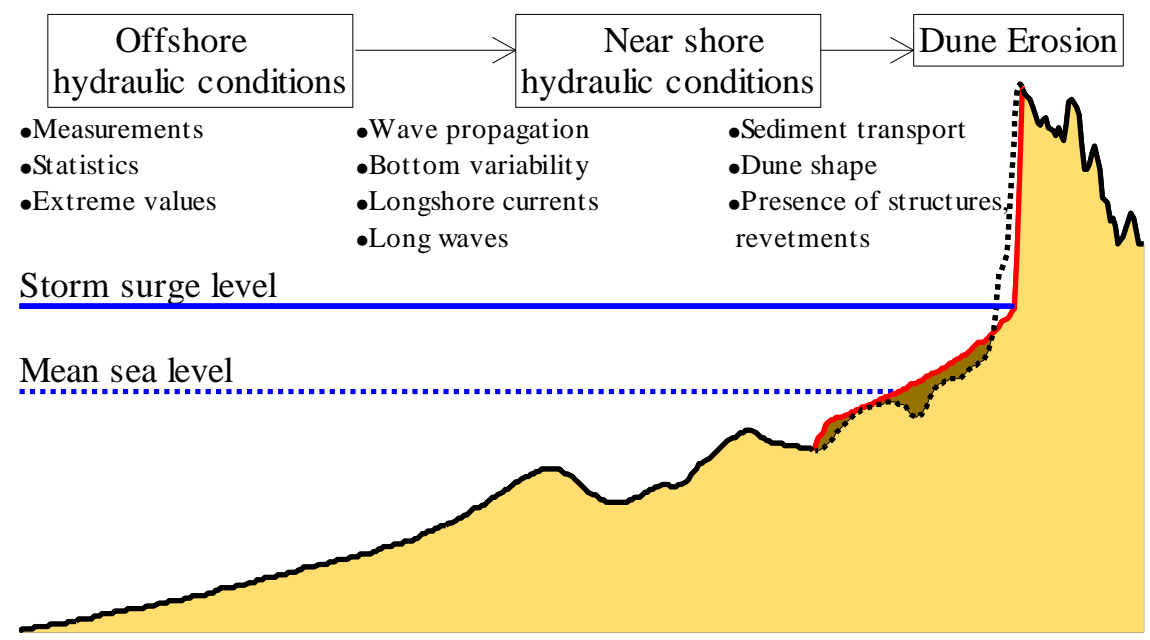

Figure 1 Process chain

The hydraulic conditions at deep water are dominated by wind and tide. Since the main interest goes to extreme values, statistics and extrapolation need to be applied to actual measurement data over a relatively short period.

When going shoreward, wave propagation is important, related to currents and bottom position. Taking this into account, near shore hydraulic conditions can be derived, at the boundary of the area of actual concern.

In the area further shoreward, sediment transport plays an important role leading to redistribution of the sediment over the profile, and so to dune erosion. Dune shape and bottom position, both in cross-shore and longshore direction play a role here. 
From the rough outline of the dune erosion process chain, as given above, many variables and processes can be identified which play a role in the resulting dune erosion. However, simply including many variables and processes in a very detailed model does not automatically reduce the uncertainty of the final result. This is because of the fact that most of the variables need to be described as stochastic to incorporate their uncertainty, leading to many contributions to the overall uncertainty. Introducing more detailed processes and associated variables, with respect to a more coarse approach, can only be beneficial in terms of uncertainty when this reduces the overall uncertainty.

\section{Exploration}

An exploration will be carried out to select aspects that qualify for further research. This can lead to improved representation of currently included aspects or to inclusion of additional aspects or a combination of both.

With a sensitivity analysis, using the current model, it can be shown which of the variables contribute, and what extent, to the final result. A sensitivity analysis, using a similar set up, but with another dune erosion model gives insight in the influence of the model representation on these sensitivities. Initially a schematized situation can provide insight, but also special cases, where the different models may lead to different results need to be considered. An example of such a special case is a situation with a bar in front of the coast. The DUROS+ model will predict approximately the same amount of erosion in a similar profile without the bar, since it uses the offshore hydraulic conditions only. A process based model, on the other hand, takes the wave propagation into account and bases the amount of dune erosion on a milder wave climate behind the bar. Including this kind of special cases in the exploration might lead to different conclusions about the performance of the current safety assessment method, depending on the situation. Similar performance of the method for all relevant types of situations would be preferable.

Apart from the sensitivity analysis with the current model approach as a starting point, also inclusion of additional aspects can be explored in a similar way. For this category a distinction has to be made between aspects which are included in the model to be used, and aspects which are not (and maybe even that poorly understood that there is no model available yet which includes it). For the first category, the approach can be rather straightforward and similar to the exploration of the variables currently taken into account. Including their forcing variable(s) as stochastic variable(s) when carrying out the sensitivity analysis gives insight in their contribution to the final result. The influence of other aspects, which are not included as such in the available models, needs to be estimated in this exploration. Possibly further research can lead to adjustment of these estimates. An example of such an aspect is the effect of alongshore variation in dune height. Calculated retreat distances for several neighboring cross-sections along such a coastal stretch can vary considerably, whereas in practice usually a straight dune front is observed after a storm. A first estimate to 
include this kind of smoothing alongshore (even in a 2D model) is to apply an averaging procedure to neighboring cross-sections. If it turns out that this has a significant effect, this can be investigated in more detail, for instance by applying a 3D model.

\section{Sensitivity analysis}

The calculation values for the actual safety assessment of the Dutch dune coast are based on a full probabilistic investigation (WL | Delft Hydraulics, 2007a). The model, as applied in that investigation, has been used as a reference situation for the sensitivity analysis as presented in this paper.

For the investigation as presented here a simplified cross-shore profile has been used (Figure 2), considered as more or less representative for most of the Dutch coast.



Figure 2 Reference profile and definition of retreat distance

Based on samples from the distributions of water level, wave height, wave period and grain size, a dune erosion computation is carried out. For this first and main step of the computation, two different dune erosion models are applied: 1) the empirical DUROS+ model, and 2) the process based DUROSTA model. Relative to the resulting erosion volume above the water level (volume A in Figure 2, enclosed by the initial profile, the water level and the dotted line), a volume $\Delta \mathrm{A}$ (between dotted and dashed line) is enclosed by moving the dune front in horizontal direction to contribute for model inaccuracy and variation in storm duration. The horizontal distance between the resulting dune edge and the MSL $+5 \mathrm{~m}$ contour of the initial profile is defined as the retreat distance.

The hydraulic conditions are based on the statistics for Hoek van Holland along the Dutch coast. For the water level distribution, a so-called conditional 
Weibull distribution function is applied, as depicted in Figure 3 (see among others RIKZ (2000) for more details).

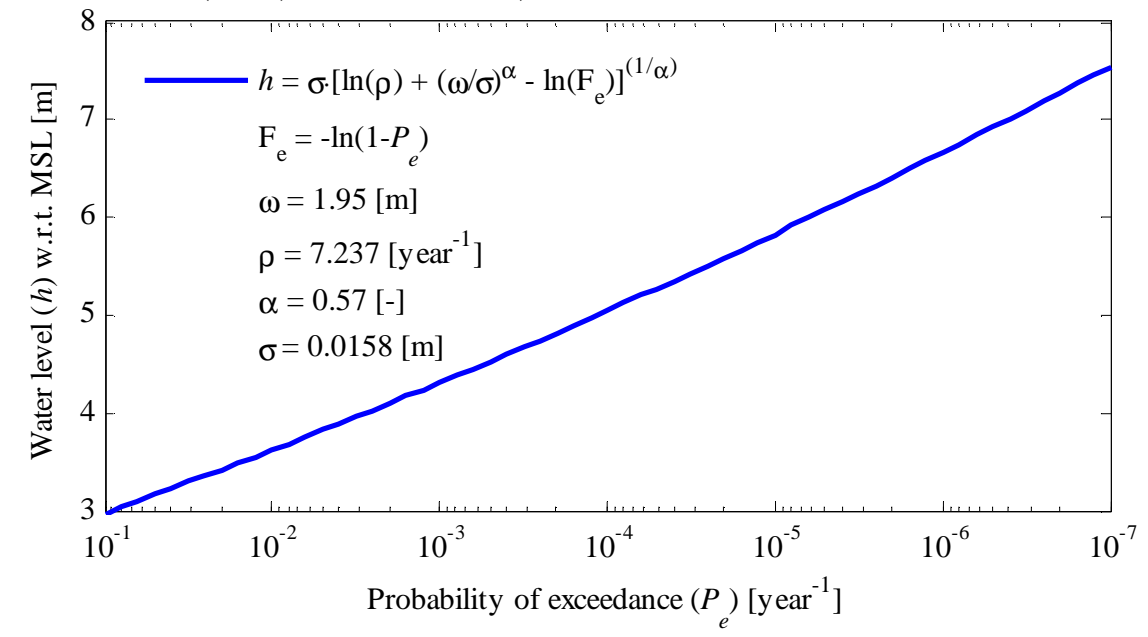

Figure 3 Conditional Weibull distribution for the water level

In the expression showed in Figure 3 is:

$F_{e} \quad$ frequency of exceedance of the highest level $h$ during a storm surge [year ${ }^{-1}$ ]

$h \quad$ highest water level during a storm surge [m]

$P_{e} \quad$ Probability of exceedance [year $\left.{ }^{-1}\right]$

$\alpha \quad$ shape parameter that depends on the location along the coast

$\omega$ threshold above which the function is valid [m above MSL]

$\sigma \quad$ scale parameter that depends on the location along the coast

$\rho \quad$ frequency of exceedance of the threshold level $\omega$ [year ${ }^{-1}$ ]

Please note the difference between frequency of exceedance and probability of exceedance. The frequency of exceedance expresses the number of exceedances per unit of time, which can be larger than one (for large probabilities). The probability of exceedance, on the other hand, expresses the probability of at least one exceedance per unit of time (always between zero and one). Using the Poisson formula, it is possible to translate probability into frequency and vice versa. The Poisson formula reads:

$$
P[N(t)=n]=\frac{e^{-\lambda t}(\lambda t)^{n}}{n !}
$$

Where:

$N(t)$ number of occurrences per unit of time [year $\left.{ }^{-1}\right]$

$n \quad$ number of occurrences

$\lambda \quad$ average number of occurrences per unit of time $\left(=F_{e}\right)$ [year $\left.{ }^{-1}\right]$

$t \quad$ time [year]

$P \quad$ Probability of occurrence $\left[\right.$ year $\left.^{-1}\right]$ 
For an arbitrary probability of exceedance $P_{e}$ (one or more occurences per unit of time), the probability of no occurrences can be written as:

$$
P[N(t)=0]=\frac{e^{-\lambda t}(\lambda t)^{0}}{0 !}=e^{-\lambda}=1-P_{e}
$$

When replacing $\lambda$ by $F_{e}$ in Equation (2), the relation between $P_{e}$ and $F_{e}$ as given in Figure 3 can be found. For a water level larger than MSL+3m $\left(P_{e}<10^{-1}\right)$, the difference between frequency and probability of exceedance is negligible.

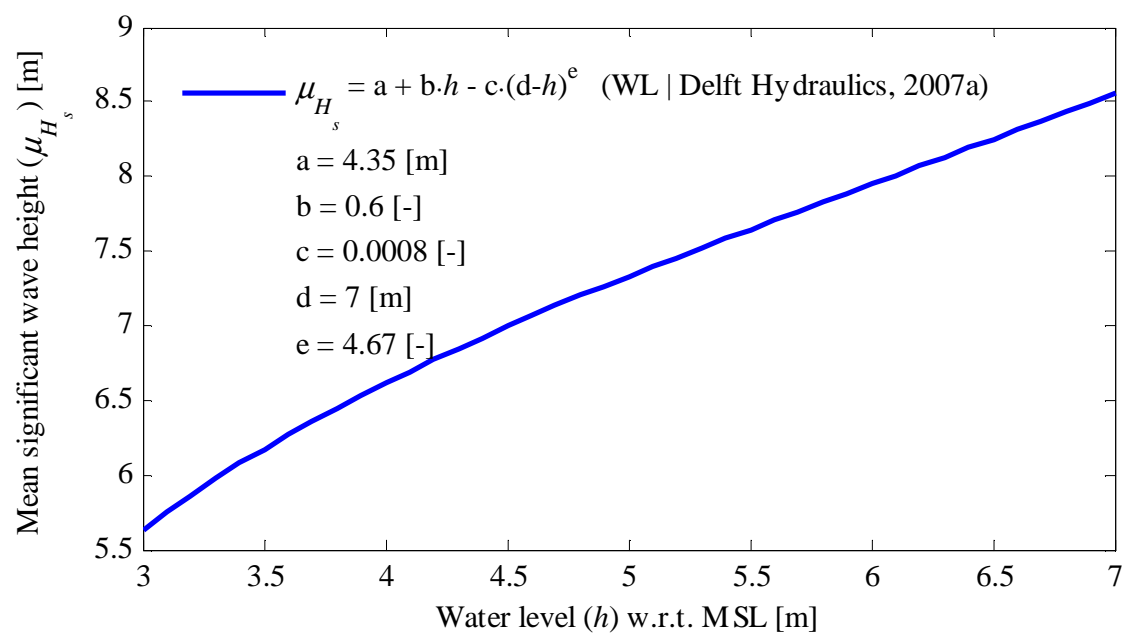

Figure 4 Relation between water level and mean wave height

The wave height is described by a normal distribution in which the mean value is related to the water level (see Figure 4) and the standard deviation is $60 \mathrm{~cm}$.

The peak wave period is also described by a normal distribution where the mean value is related to the wave height (Figure 5), and the standard deviation is $1 \mathrm{~s}$. 


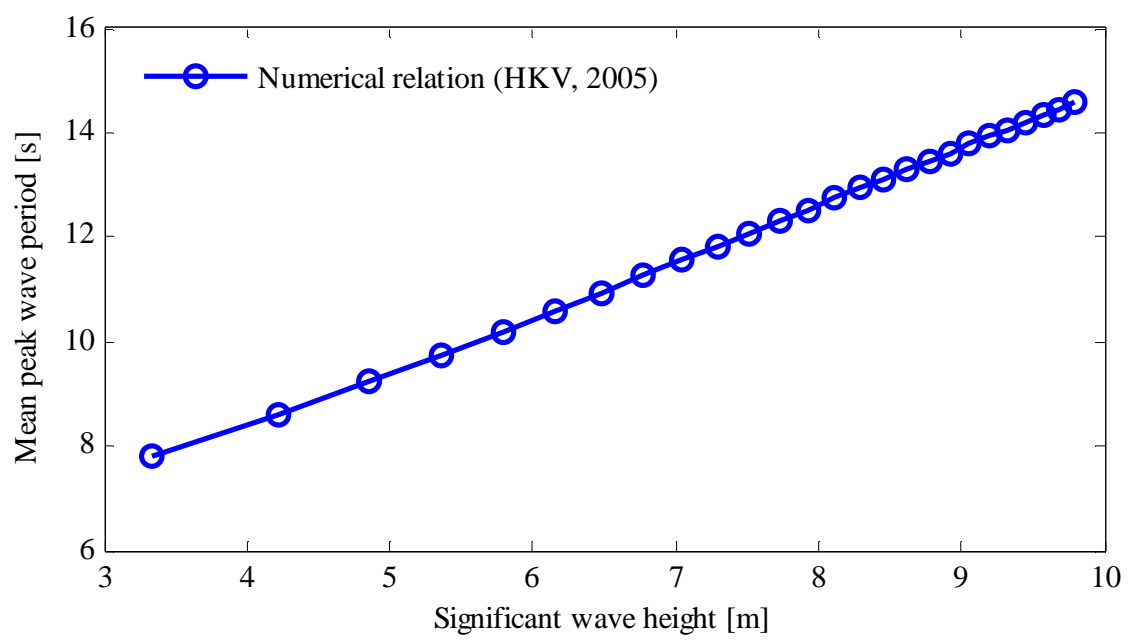

Figure 5 Numerical relation between Significant wave height and peak wave period

An overview of the stochastic characteristics as applied in the reference situation is given in Table 1. The First Order Reliability Method (FORM), available within the probabilistic toolbox Prob2B (Courage and Steenbergen, 2005), has been applied to derive the probability of exceedance for a predefined threshold value of the retreat distance. This threshold value can be considered as the (artificial) limit state, realizations resulting in larger retreat distances are considered as failure. The FORM calculation finally results in the probability of exceedance of that threshold retreat distance. FORM calculations have been carried out for a series of threshold retreat distances ranging from $25 \mathrm{~m}$ to $100 \mathrm{~m}$. Based on the results from that, the retreat distance for a probability of failure of $10^{-5}$ per year can be found by interpolation.

Table 1 Stochastic characteristics for the reference situation (WL | Delft Hydraulics, 2007a)

\begin{tabular}{|l|l|l|l|}
\hline Variable & Mean value & $\begin{array}{l}\text { Standard } \\
\text { deviation }\end{array}$ & Distribution type \\
\hline Water level $(h)$ & \multicolumn{2}{|c|}{ Specified in Figure 3 } & $\begin{array}{l}\text { Conditional } \\
\text { Weibull }\end{array}$ \\
Wave height $\left(H_{s}\right)$ & $\mathrm{f}(h)$ See Figure 4 & $0.6 \mathrm{~m}$ & Normal \\
Wave period & $\mathrm{f}\left(H_{s}\right)$ See Figure 5 & $1 \mathrm{~s}$ & Normal \\
Grain size & $225 \mu \mathrm{m}$ & $10 \%$ of mean & Normal \\
& & $(22.5 \mu \mathrm{m})$ & \\
Surge duration & 0 & $10 \% * \mathrm{~A}$ & Normal \\
Model accuracy & 0 & $15 \% * \mathrm{~A}$ & Normal \\
\hline
\end{tabular}


Using the results based on the stochastic characteristics from Table 1 as a reference situation, each of the stochastic characteristics has been varied, keeping the others to their reference values. For each of these newly created sets of stochasts, the retreat distance for the $10^{-5}$ per year probability of exceedance has been derived.

\section{RESULTS}

Figure 6 gives an overview of the probabilities of exceedance for a series of retreat distances for both DUROS+ and DUROSTA. The retreat distance for a probability of exceedance of $10^{-5}$ has been highlighted, these will be the reference for the sensitivity analysis results presented below. It is clear that the results for both models differ considerably. These differences are in the same order of magnitude as found in a deterministic comparison of DUROS and DUROSTA by WL | Delft Hydraulics (1992).

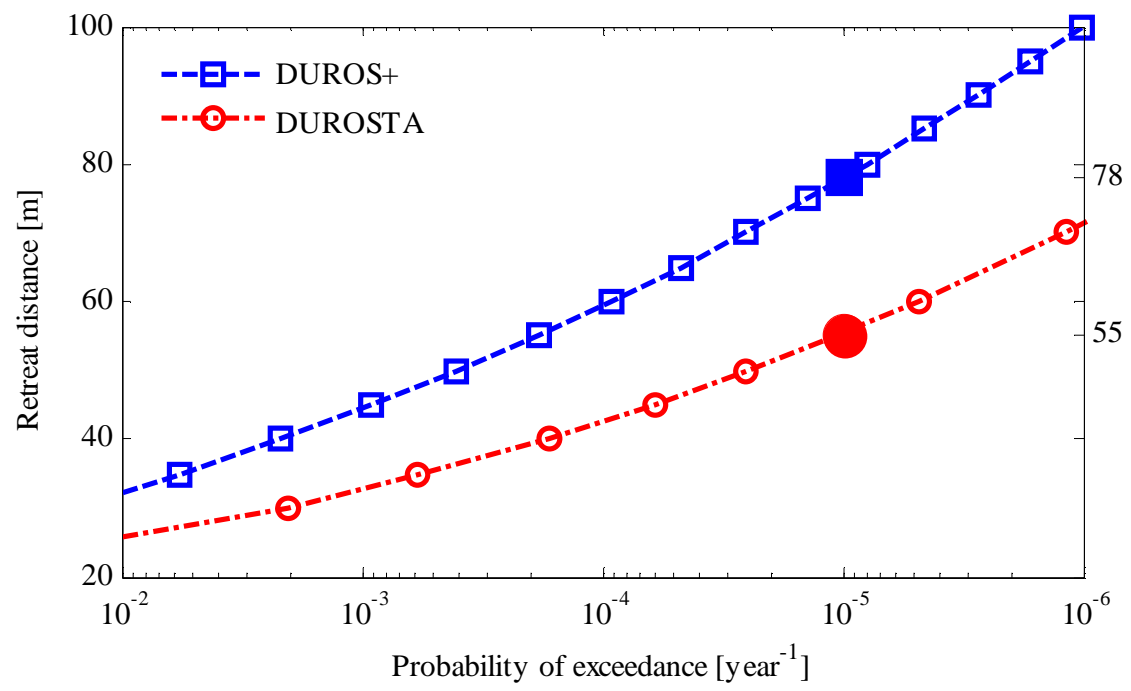

Figure 6 Probability of exceedance for reference situation

Figure 7 shows a set of simulations where the water level has been changed for all probabilities of exceedance with the same value. As clearly appears from this figure, the water level has significant influence on the $10^{-5}$ per year retreat distance for both models. In fact this investigation could be seen as some kind of fictitious sea level change. However, in case of real sea level change, it will change gradually, allowing the profile to adapt itself (Bruun, 1962). This has, depending on the rate of sea level change, a reduced effect. The behavior for a changed water level is similar for DUROS+ and DUROSTA. 


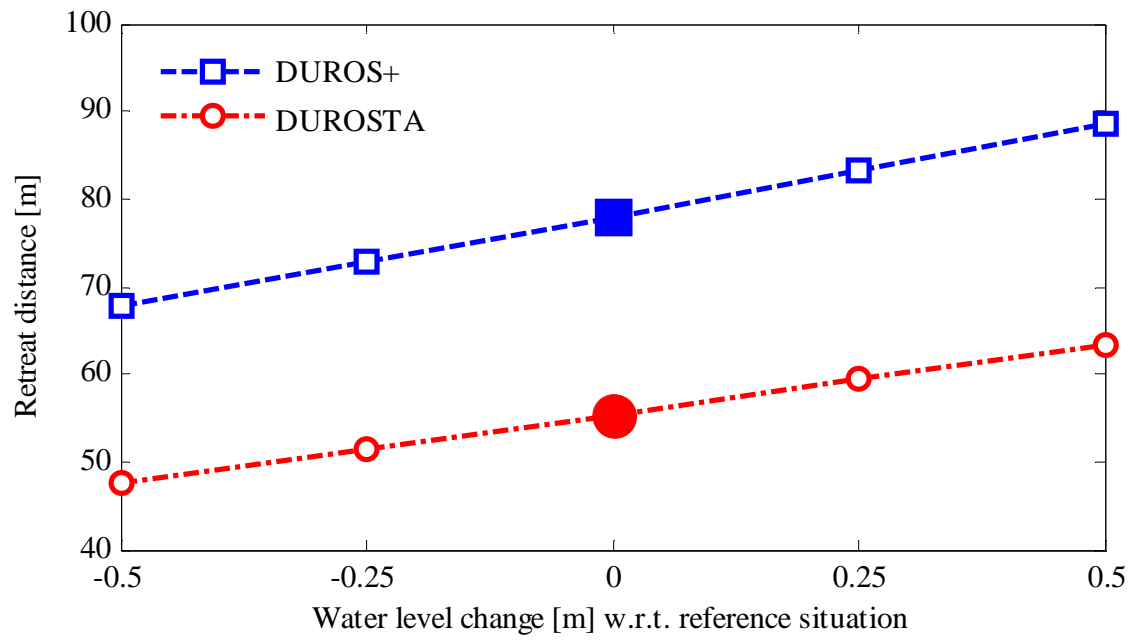

Figure 7 Sensitivity for water level change

Figure 8 shows for both models a reduced $10^{-5}$ per year erosion (retreat distance) for increased mean grain sizes. Note that the absolute value of the standard deviation of the grain size is larger for increasing grain sizes (set to $10 \%$ of mean). Figure 9 shows the effect of the magnitude of the standard deviation. A large standard deviation results in a larger retreat distance. So, the effect of the mean grain size is reduced due to the counteracting effect of the standard deviation. Nevertheless, the mean grain size still has much influence. In reality, the shape of the initial profile will also depend on the grain size. This will also have a counteracting effect, since coarser sediment will allow a steeper profile which can result in more erosion.

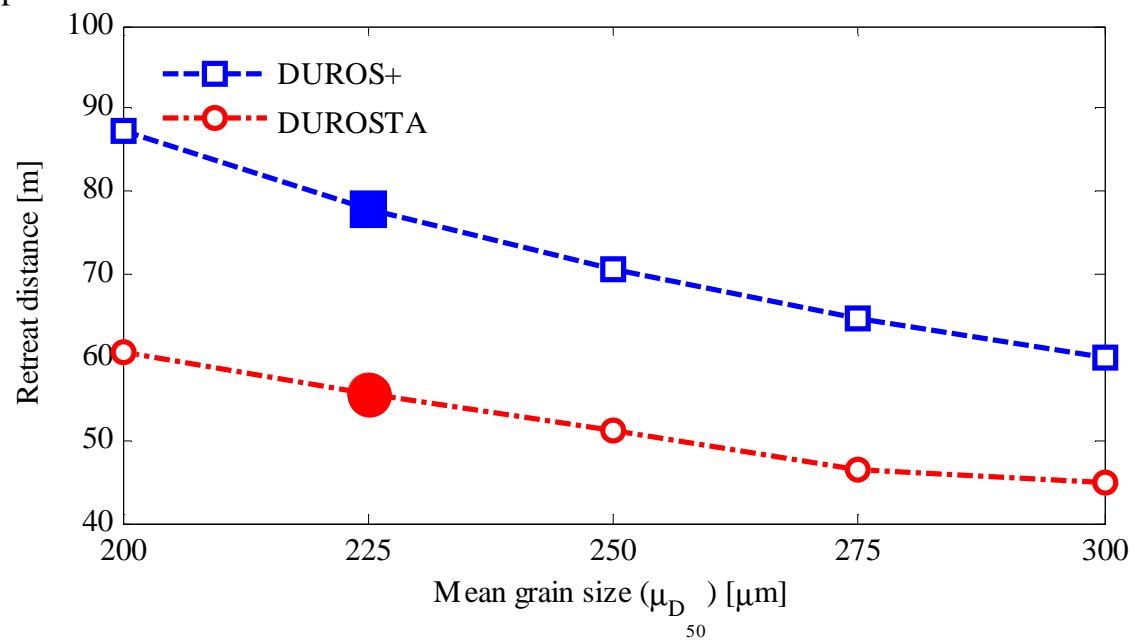

Figure 8 Sensitivity for mean grain size 
The sensitivity of the $10^{-5}$ per year retreat distance for the mean peak wave period is especially significant for increases of more than $3 \mathrm{~s}$ (w.r.t. the reference situation). When increasing the mean peak wave period with $6 \mathrm{~s}$, the $10^{-5}$ per year retreat distance increases from $78 \mathrm{~m}$ to $87 \mathrm{~m}$ (DUROS+). Varying the mean values of the wave height, storm duration contribution and the model accuracy hardly influences the $10^{-5}$ per year retreat distance.

As long as the standard deviation of the grain size is between zero and the reference value of $22.5 \mu \mathrm{m}$, for a fixed mean grain size of $225 \mu \mathrm{m}$, the influence is only small (Figure 9). However, if the standard deviation of the grain size further increases, the increase of the $10^{-5}$ per year retreat distance is more clear.

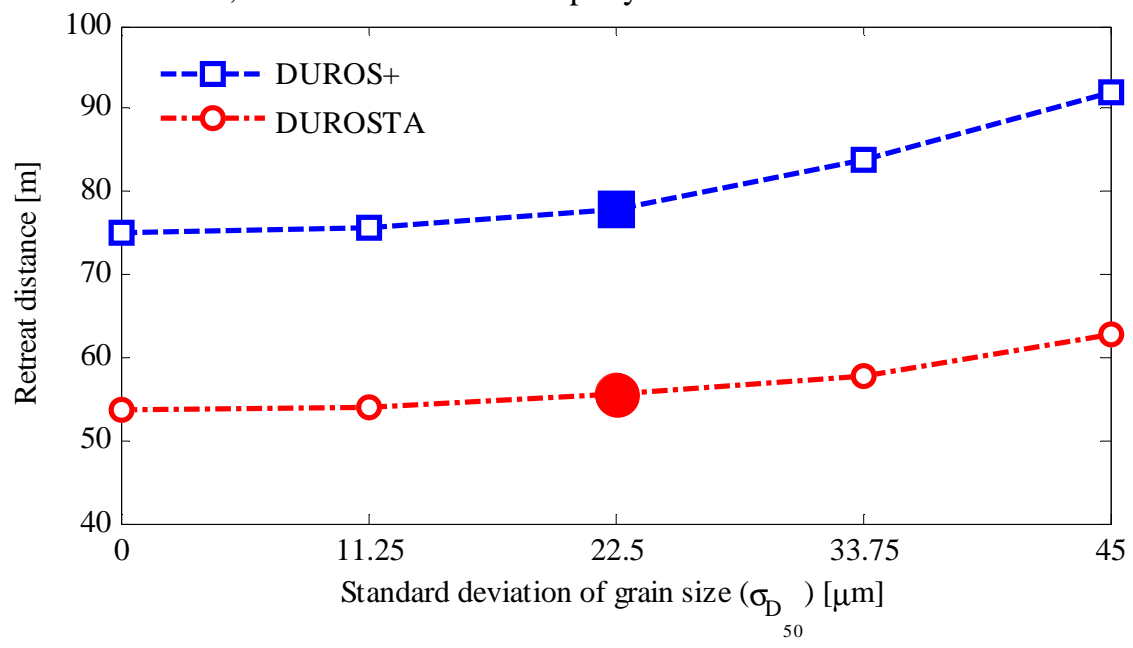

Figure 9 Sensitivity for standard deviation of grain size for a mean grain size of $225 \mu \mathrm{m}$

The sensitivities for the standard deviations of the other variables which have been investigated all resulted in only small influences on the $10^{-5}$ per year retreat distance. The sensitivity of the $10^{-5}$ per year retreat distance for the standard deviation of the peak wave period is an example of a standard deviation which has hardly any influence (Figure 10). This does not mean that these variables are obsolete in the probabilistic model, but a discrepancy in their standard deviations does only cause a small difference in the result. 


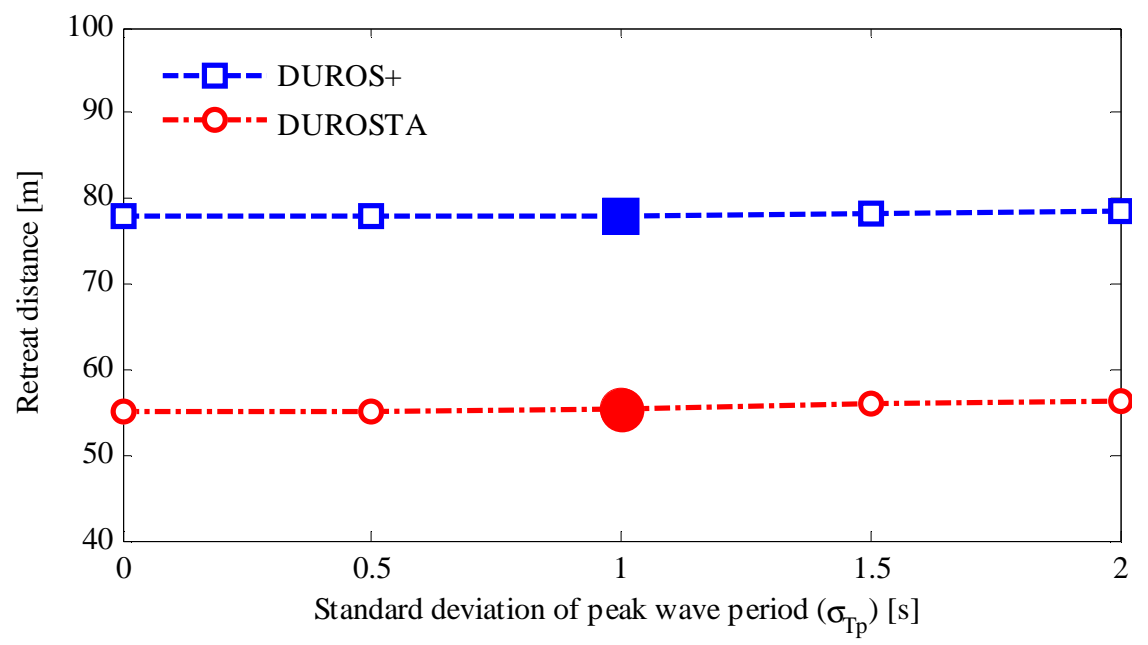

Figure 10 Sensitivity for standard deviation of peak wave period

\section{CONCLUSIONS}

This paper describes a probabilistic sensitivity analysis using the background of the present Dutch safety assessment method for dunes as a reference. To put this in the right perspective, also the approach to reduce the uncertainty in the prediction of dune erosion during extreme conditions has been described, of which the sensitivity analysis is one of the first steps.

The main conclusions from the sensitivity analysis are:

The sensitivity of the rate of dune erosion (in terms of retreat distance) with a probability of exceedance of $10^{-5}$ per year for variation in stochastic characteristics (mean values and standard deviations) is similar for the empirical model DUROS+ and the process based model DUROSTA.

DUROSTA results for all cases in considerably less erosion than DUROS+, which is in agreement with the findings of WL | Delft Hydraulics (1992) in a deterministic comparison of DUROS and DUROSTA.

For both DUROS+ and DUROSTA, the mean values of water level, grain size and peak wave period as well as the standard deviation of the grain size turn out to be the most important.

Therefore, especially stochastic characteristics of the water level, grain size and peak wave period need to be based on proper field data.

The other variables do have their contribution, but some discrepancy in their stochastic characteristics does not cause major changes in the final prediction of dune erosion.

\section{ACKNOWLEDGMENTS}

Rijkswaterstaat Waterdienst is gratefully acknowledged for taking part in financing the Ph.D. research related to the work as published in this paper. 


\section{REFERENCES}

Bruun, P. 1962. Sea-level rise as a cause of shore erosion. Journal Waterways and Harbours Division, vol. 88(1-3), pp. 117-130.

Courage, W.M.G. \& H.M.G.M. Steenbergen, 2007. Prob2B $B^{\mathrm{TM}}$ : variables, expressions and Excel®. Installation and Getting Started. TNO-report 2007-D-R0887/A, TNO Built Environment and Geosciences, Delft. August 2007.

HKV, 2005. Deep water boundary conditions (ELD, EUR, YM6, SCW en SON). HKV consultants (prepared for RIKZ) (in Dutch). July 2005.

RIKZ, 2000. Direction dependent extreme values for high water levels, wave height and wave period. Report RIKZ 2000.040 (in Dutch).

Steetzel, H.J., 1993. Cross-shore Transport during Storm Surges. Ph.D. Thesis Delft University of Technology, ISBN 90-9006345-5.

Technical Advisory Committee on Water Defences / TAW, 1984. Guide to assessment of the safety of dunes as a sea defence. Centre for Civil engineering Research and Codes (CUR) 140, Gouda, The Netherlands.

WL | Delft Hydraulics, 1992. Comparison DUROS/DUROSTA.

WL | Delft Hydraulics report H1201-II (in Dutch). December 1992.

WL | Delft Hydraulics, 2007a. Dune erosion; Product 3 - Probabilistic dune erosion method. WL | Delft Hydraulics report H4357. February 2007.

WL | Delft Hydraulics, 2007b. Technical report dune erosion; Safety assessment of dunes as water defence for the safety assessment guidelines 2006 (in Dutch). May 2007. 